\title{
3D MODELING OF ROMAN BRIDGE BY THE INTEGRATION OF TERRESTRIAL AND UAV PHOTOGRAMMETRIC SURVEY FOR STRUCTURAL ANALYSIS PURPOSE
}

\author{
Pepe M. ${ }^{1, *}$, Costantino D ${ }^{1}$., Crocetto N. ${ }^{2}$, Restuccia Garofalo A. ${ }^{3}$ \\ ${ }^{1}$ DICATECh, Polytechnic of Bari, Italy \\ ${ }^{2}$ Università degli Studi della Campania Luigi Vanvitelli, Italy \\ ${ }^{3}$ AESEI spin-off, Polytechnic of Bari, Italy
}

\section{Commission II}

KEY WORDS: photogrammetry, UAV, masonry bridges, FEM, structural analysis

\begin{abstract}
:
The 3D survey of the masonry bridges is rather complex and may require the integration of terrestrial and aerial surveys. In fact, in order to perform the survey of the superstructure of a bridge, the photogrammetric survey may be realized by the use UAV (Unmanned Aerial Vehicle) since it allows acquiring all the details of the upper part of the bridge. Indeed, especially the extreme lateral parts of the bridge cannot be performed through a traditional terrestrial survey. In addition, the UAV photogrammetry allows speeding up and optimizing work. As regards the terrestrial survey, instead, it has the advantage of being able to use highly performing optics and cameras (high resolution of the sensor, stabilized optics, etc.). However, these types of sensors are quite heavy and, in general, could not be mounted on an aerial platform on commercial and low-cost drones. In any case, beyond the payload of common commercial drones at low cost, there is also the problem that the digital cameras mounted on the UAV platforms cannot observe the arches of the bridge from the bottom upwards by low-cost tools. Therefore, a simple way to build a unique 3D model consists in the integration of terrestrial and aerial surveys; in this way, using a suitable procedure, sensor and software based on the Structure from Motion (SfM) and Multi View Stereo (MVS) approaches, it was possible to build detailed, precise and textured three-dimensional models of structures, such as the buildings, historical artefact, bridges etc.

In this paper, a case study concerning the construction of a three-dimensional model according a photogrammetric method of a Roman bridge is discussed. In particular, the bridge taken under investigation, belong to the Cultural Heritage, is called "San Cono" and is located in south of Italy. After built the 3D model of masonry bridge (3D point cloud and 3D mesh), it was identified a special procedure that allowed to obtain the model of the bridge suitable for a structural analysis within of dedicate software.
\end{abstract}

\section{INTRODUCTION}

The development of algorithms based on the SFM (Structure from Motion) approach made it possible to orientate numerous images of the object to be investigated with high level of automation, without the need to know "a priori" information and, at the same time, to use rigorous geometric and stochastic models developed through traditional photogrammetry. Once obtained the camera poses, it is possible to apply MVS (Multi-ViewStereo) algorithm. This latter algorithm allows to increase the density of points starting from the point cloud generated in SfM process. Therefore, Image-based modelling (IBM) allows to obtain measurements and 3D models from images (Luhmann et al., 2007). For this reason, the IBM approach were applied with success in building 3D models in diverse fields and using several sensors. Generally, the workflow that allows to produce 3D reconstructions/3D models in most common photogrammetry software may be synthesized as (Rahaman \& Champion, 2019): (i) Image acquisition (or adding photos), (ii) Feature detection, matching, triangulation (or align photos) (iii) Sparse reconstruction, bundle adjustment (or point cloud generation) (iv) Dense correspondence matching (or dense cloud generation) (v) Mesh/surface generation, and (vi) Texture generation. Recently, the combination of SfM algorithms (Remondino, 2013; Angelini et al., 2017; Murtiyoso et al., 2018) and aerial images obtained by UAV (Unmanned Aerial Vehicle) platform has revolutionized photogrammetric surveying, allowing obtaining 3D models through low-cost, fast and high quality data acquisition and processing (Cucchiaro et al., 2018).

In addition, the use of UAV is really useful in critical scenarios, where the easy transportability and low cost of the necessary equipment for aerial survey compared to laser scanning techniques represent a great advantage. Actually, there are on the market many commercial UAV aerial platform solutions for the photogrammetric survey.

Some examples of UAV aerial platforms are the Xiaomi Mi Drone 4K UHD WiFi FPV (Figure 1.a), 3D Robotics Aero-M Drone (fixed wings) supplied with Canon PowerShot S100 (Figure 1.b), SwissDrones Dragon 50 V2 equipped with Leica RCD30 (Figure 1.c), DJI's M600 and M600-Pro (hexacopter) drones integrated with Phase One aerial cameras (Figure 1.d), SenseFly UAV (fixed wings) (Figure 1.e).

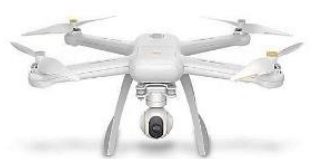

(a)

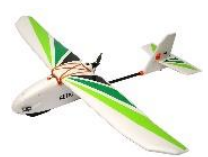

(b)

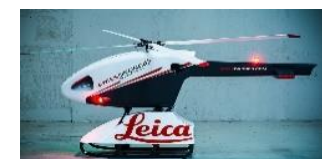

(c)

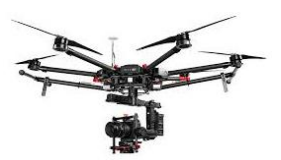

(d)

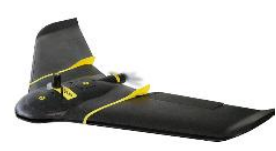

(e)

Figure 1. Examples of UAV aerial platforms.

\footnotetext{
* Corresponding author: massimiliano.pepe@poliba.it
} 


\subsection{Related works}

The use of IBM approach in order to construction 3D models of bridges for the representation or structural analysis is becoming increasingly widespread over the years.

Şeker et al., 2006 have developed a terrestrial photogrammetry method to obtain virtual model of Kapuağas bridge. In this case study, a Samsung Digimax 430 digital camera featuring 4.3 mega pixels and Pictran-D digital photogrammetric software were used in building of 3D model of the masonry bridge.

Jáuregui et al. 2006 proposed a special procedure for bridge inspections and Historic Bridge documentation. The historic bridge digital documentation study was carried out by the use of Kodak DCS660 camera, which has a solid-state CCD (charged coupled device) image sensor with a 6.1 megapixel (3048 x 2008 pixels) resolution. The photogrammetric $\mathrm{p}$ was carried out using PhotoModeler commercial software.

Lorenzo et al., 2006 discussed a multidisciplinary approach to heritage documentation involving Close Range Photogrammetry (CRP) and, in particular, the usefulness of CRP in the accurate 3D modelling and crack detection. In this case study, the 3D model of the Fillaboa Bridge was created using a Canon EOS 10D DSLR camera. The 3D model was generated in PhotoModeler software.

Jiang et al., 2008 wrote a review about the major aspects of photogrammetry bridge measurement. As consequence, the paper describes the measurement types, cameras, targets, network control and software in the bridge environment.

Altuntas et al., 2017 wrote a method for 3D reconstruction of the Meran bridge (Turkey). The survey was carried out with a Canon PowerShot A2200 digital camera and a total amount of 189 images were acquired. The post-processing of the image was performed with Photomodeler software.

Kouimtzoglou et al., 2017 discussed the reconstruction of the Plake bridge, in Greece. In this case study, using terrestrial images, the 3D model of the bridge was realized using Agisoft Photoscan Pro software. Starting from the model obtained in this way, the masonry arches structure was analysed using the FEM (Finite Element Method) approach.

Calì et al., 2018 wrote about the survey of the "Saracens" masonry bridge located in Adrano (Italy). The contribute of UAV photogrammetry was crucial in order to survey the upper and lateral part of the bridge.

\section{METHOD AND SENSORS}

\subsection{Method}

The first step in building 3D model is the choice of the Scale of Representation (SR) of the masonry bridge. In addition, taking into account the graphical error drawing (generally established in $0.2 \mathrm{~mm}$ ), it is possible to calculate the Graphical Error (EGR) as the product between the SR and the graphic drawing error. Therefore, once established the tolerable error, the next step consisted in the determination of the Ground Sample Distance (GSD). As it is known, the GSD of the image can be calculated by the following equation:

$$
G S D=\frac{H}{c} C C D \text { pixel size }
$$

where:

$\mathrm{H} \quad$ flight height (or distance from the target to sensor); CCD pixel size dimension of the sensor.
In order to obtain a final GSD value lower than the tolerance provided for by the project, in general two times the Graphical Error, a value of half of the originally planned GSD was chosen (Pepe, 2018a). In this way, it was possible to design the flight planning on the masonry bridge. Indeed, especially in the aerial survey, the relation (1) is particularly useful to calculate the flight height of the UAV. However, even in the terrestrial survey, it is necessary to pay attention in order to acquire images with a GSD not higher than the project one.

The images were imported into photogrammetric software to build 3D model of masonry bridge. Subsequently, to scale the model of the bridge to real dimensions, it was necessary to perform a topographic survey. This last aim was reached using total station instruments featuring the precision required by the project.

Once obtained the 3D model, it must be cleaned from the several elements that do not characterize the structure of the bridge, such as vegetation, antennas, photovoltaic panels, bar for measuring the water level of the river etc.

Therefore, once obtained a clean model, it can be imported in further software for structural analysis and functional restoration. The pipeline that describes these last steps just described, is reported in the Figure 2.

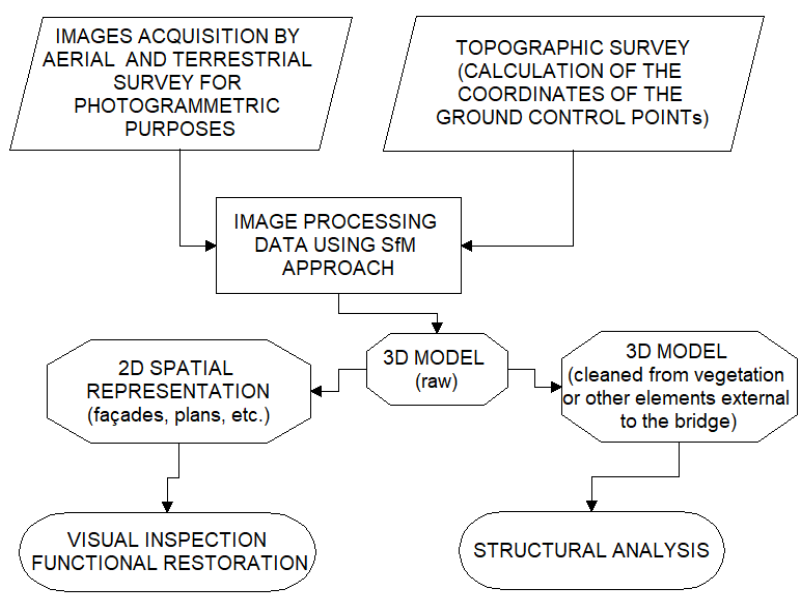

Figure 2. Workflow of the SfM approach used in order to build 3D models and further possible structure analysis

\subsection{Sensors}

Nowadays, the use of new passive sensor technologies for photogrammetric survey is constantly evolving. Considering the stability of the lens and the high performance of the sensors, digital Single-Lens Reflex (dSLR) cameras, these types of sensors are always widespread in the field of surveys. For this experimentation, photogrammetric survey was carried out by the use of Canon dSLR EOS 100D digital camera with $18 \mathrm{~mm} \mathrm{f/3.5-}$ 5.6 IS STM lens.

Furthermore, another camera taken into consideration is the one provided with Xiaomi Mi Drone 4K UHD WiFi FPV Quadcopter drone that was used for aerial detection of bridges. The built-in optical sensor with the drone is a $4 \mathrm{~K}$ camera, which is capable of capturing images in the size of 12.4 effective (3840 x 2160 pixels). The camera is a realized by $1 / 2.3$ inch CMOS (complementary metal-oxide semiconductor) sensor and an Ambarella micro-processor mounted on a 3-axis gimbal direct drive and shoots up to $4 \mathrm{~K}$ resolution. 


\section{CASE STUDY OF SAN CONO'S BRIDGE}

\subsection{Location and brief history of the San Cono's bridge}

The SfM-MVS approach was applied in the relief of masonry road bridges built at the end of the 1800s. San Cono's bridge, over the Bianco river located in the municipality of Buccino (in southern Italy), was considered for the experimentation (Figure 3).

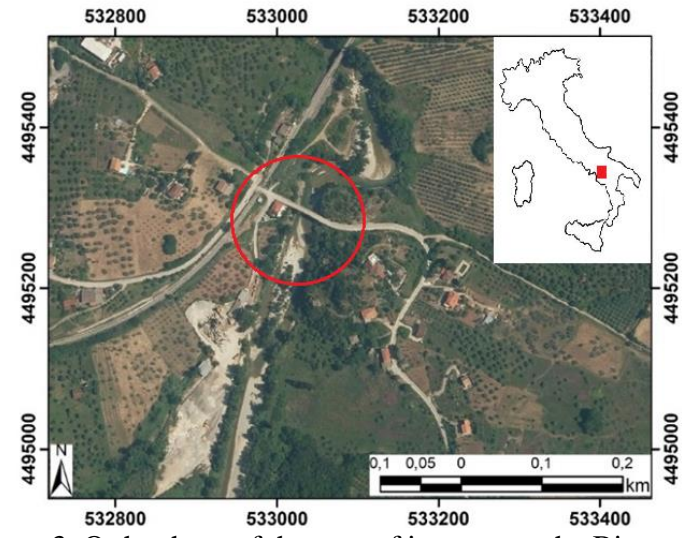

Figure 3. Orthophoto of the area of interest on the Bianco river (latitude $40^{\circ} 36 ' 27.84$ "N; longitude $15^{\circ} 23 ' 25.81 " \mathrm{E}$ )

San Cono's bridge, as reported by the inscription on the bridge, can be dated to the Augustan age. The "Volceiani, Municipes et Incolae" collected the money needed to build the bridge in order to reach the city from neighboring countries. The route separated from the "Rhegio - Capuam" road to the "Taverna Cerreta" and headed north. The work is remembered since the sixteenth century for the ancient inscription repeatedly repeated on it, which celebrated its construction: it was engraved on tables surmounting the top of an arch where the erection and testing are remembered (figure 4.a). Originally, the bridge had a pronounced donkey-back profile with two shoulders and a steep slope at the ends and a pylon with a triangular rostrum, as shown in an eighteenth-century print (figure 4.b).

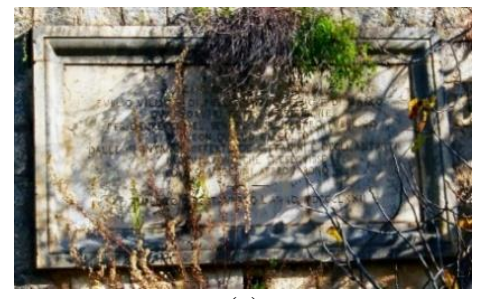

(a)

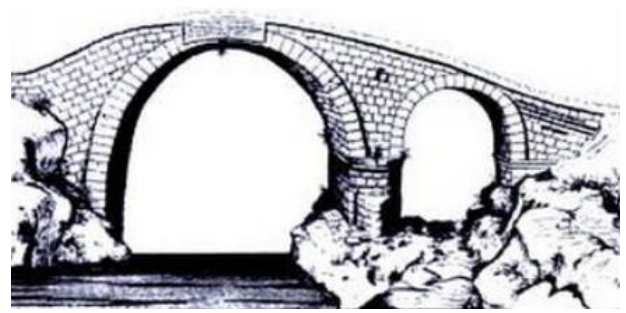

(b)

Figure 4. Historical information on the bridge. a) table on the bridge; b) image of the original structure of the bridge taken from the book "Strade romane, ponti e viadotti", Quilici, L., \& Gigli, S. Q.,1996

The current shape of the bridge is incorporated into a new bridge, which in 1872 levelled the road and widened the site (taking it from $3.20 \mathrm{~m}$ to $6.45 \mathrm{~m}$ ), covering it, so as to leave only the original arches visible, below the new ones. In this way, the intervention represented an exceptional example of respect for the ancient monument.

From the architectural point of view, the bridge has two spans of unequal light, for a total length of $40 \mathrm{~m}$. Part of the ancient arches can still be seen below the nineteenth-century one, which changes its profile.

The central round arch has a light of $17.3 \mathrm{~m}$ and at the base there are five projecting brackets with three others at a higher altitude to complete the support of the rib; the minor arc has a light of 5.9 $\mathrm{m}$ with three shelves.

The central pile, about $9.20 \mathrm{~m}$ long, still presents the triangularshaped rostrum, on which the nineteenth-century brick arches are set.

The original vestments of the tympani, as can be seen in the eighteenth-century print, were in square work; today they are inserted in the new 19th century vestments, with an upper parapet that modifies the original donkey back profile.

A plaque was placed on the key of the central arch that recalls the construction of the ancient bridge and its reconstruction.

\subsection{D survey of the masonry bridge}

In order to construct the 3D model, in this case study, the photogrammetric survey was divided into the aerial and the terrestrial one.

Taking into account the Scale of Representation (SR) and the graphical error drawing (generally established in $0.2 \mathrm{~mm}$ ) it is possible to calculate the Graphical Error (EGR) as their product. Once established the tolerable error, the next step concerns the determination of the Ground Sample Distance (GSD) using the equation 1.

Therefore, taking into account a planning $G S D=1 \mathrm{~cm}$ and the features of the sensors follows that to realize this geometric resolution, the maximum distance between object and sensor is $42 \mathrm{~m}$ for the dSLR camera and $8 \mathrm{~m}$ for the camera supplied with Xiaomi Mi drone, as show in the following Table 1.

\begin{tabular}{|c|c|c|}
\hline & $\begin{array}{c}\text { Canon EOS } \\
100 \mathrm{D} \\
(\mathrm{f}=18 \mathrm{~mm})\end{array}$ & $\begin{array}{c}\text { Xiaomi Mi 4K } \\
\text { camera }\end{array}$ \\
\hline$C C D_{\text {pixel size }}(\mu \mathrm{m})$ & 4.29 & 4.54 \\
Focal length $(\mathrm{mm})$ & 18 & 3.5 \\
$H_{\max }(\mathrm{m})$ & 42 & 8 \\
\hline
\end{tabular}

Table 1. Flight height (or distance from the target to sensor) values for $G S D=1 \mathrm{~cm}$

The aerial survey was carried out with the UAS Xiaomi Mi Drone system whose weigh less than $1 \mathrm{~kg}$ and a half and the declared maximum speed is 18 meters per second (about $65 \mathrm{~km} / \mathrm{h}$ ) and was developed and produced by Flymi, a company of the Mi Ecosystem. The Xiaomi Mi Drone is equipped with a $5.100 \mathrm{mAh}$ battery and $17.4 \mathrm{~V}$. The estimated flight time in 27 minutes (25 minutes in hovering) is the flagship of a model that manages to guarantee fun and stable shooting.

In particular, the aerial survey was designed with the open source software "Mission Planner", developed by Oborne for the opensource APM autopilot project. Mission Planner is an application for the Ground Station with full functionality for the open source autopilot project called ArduPilot. The flight plan was realized with a longitudinal overlap (end-lap) of $80 \%$ and a transversal (sidelap) of $60 \%$ (Pepe et al., 2018). In addition, flight lines (FL) inclined at $30^{\circ}$ and $45^{\circ}$ were designed in a longitudinal direction to the bridge in order to increase the rigidity of the aerial photogrammetric block in the bridge part and, at the same time, 
to increase the redundancy of information with the data obtained from the terrestrial survey. In total, 285 aerial photos were taken. It should be noted that while the flight plan was designed and planned in the laboratory, the flight was carried out thanks to a company specialized in the use of SAPRs (drones) in operations in critical and non-critical areas. In fact, according to art. 8 "General provisions for operating RPAS" of Regulation of Remotely Piloted Aerial Vehicles issued by ENAC (Ente Nazionale per l'Aviazione Civile - Italian Civil Aviation Authority) the following conditions must be met (ENAC, 2018):

1. The RPAS shall be identified by a plate installed on the RPA showing the identification of the system and of the operator. An identical plate shall be installed also on the remote ground pilot station.

2. As of the 1 st of July 2016 , in addition to plates required by the Art 8.1, any RPAS shall be equipped with an Electronic Identification Device, that allows the transmission of RPA real time data, its owner/operator and basic flight parameters, as well as the recording of these data. Electronic Identification Device performances and characteristics are defined by ENAC.

3. RPAS shall be supplied with a Flight Manual or equivalent manual.

4. Specialized Operations shall comply with the provisions regarding procedures in air navigation and airspace use, laid down in Section V.

5. RPAS shall be equipped with systems/equipment necessary to carry out intended operations in compliance with the applicable rules of the air and according to the airspace class engagement. They shall be equipped with systems/equipment intended to indicate the RPA height above ground so to enable a positive check during flight.

6. For VLOS operations within un-controlled airspace, ENAC reserves the right to require the installation of lights or other means to augment the RPA conspicuity by the remote pilot or by other airspace users.

7. RPAS shall be piloted by a pilot with recognized competences and skills as per Section IV.

8. During VLOS operations, pilot shall be clearly visible and immediately identifiable by proper means. Pursuant to this Regulation, the pilot shall wear a high visibility vest with the sign RPA pilot.

9. RPAS in the scope of this section are operated for specialized operations either "non-critical" or "critical", pursuant to articles 9 and 10 .

10. RPAS operations with purpose "research and development" are subject to ENAC authorization.

The UAV used for the experimentation is the Xiaomi Mi $4 \mathrm{~K}$, a multi-copter rotary wing type that allows achieving a max flight speed of $18 \mathrm{~m} / \mathrm{s}$ with a max climbing speed of $6 \mathrm{~m} / \mathrm{s}$ and lowering speed of $1.5 \mathrm{~m} / \mathrm{s}$. The weight of the vehicle is $1250 \mathrm{gr}$.

As usual, before using an aerial platform in the airspace, it was necessary to check if it was possible to fly on the area of interest. For this reason, it was necessary to plan, from an aeronautical point of view, the flight operations in relation to the airspace. The Italian Airspace Structure is divided in 3 FIRs (Flight Information Regions): Milano, Roma and Brindisi. The area of interest is located in the Brindisi FIR. Using the Brindisi VFR (Visual Flight Rules) map (scale1:500,000) and zooming on the area of interest (Figure 5), it is easy to note that the flight zone falls inside the
CTR (Controlled Traffic Region), i.e. a volume of controlled airspace which extends from the surface to a specified upper limit, established to protect air traffic operating to and from that airport. In this zone, the Unmanned Aerial Systems Italian Regulation approved by Italian Civil Aviation Authority (ENAC) has provided restrictions on flying over these areas: weight must be less than $25 \mathrm{~kg}$, maximum distance between pilot and UAV must be $200 \mathrm{~m}$ and the maximum flight height must be $70 \mathrm{~m}$ AGL (Above Ground Level). Therefore, considering the flight planning parameters determined in the previous section, it was possible to fly with UAV also in compliance with aeronautical rules.

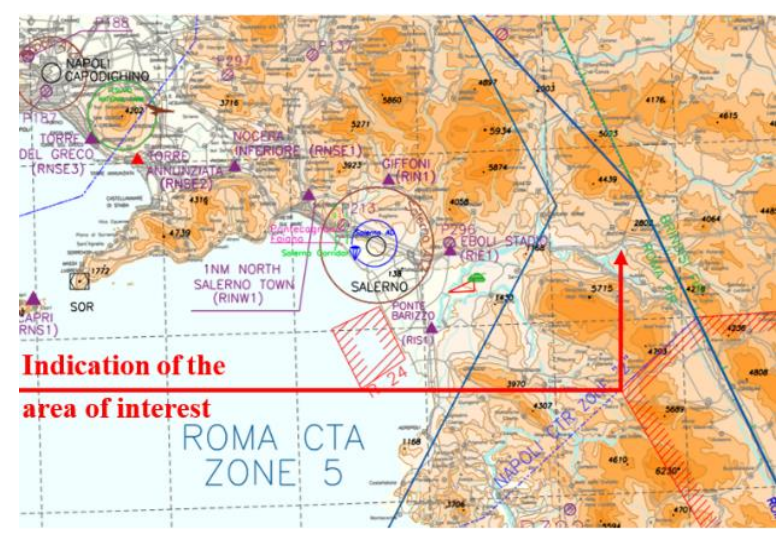

Figure 5. Indication of the AOI on VFR chart

As concern the terrestrial survey, it was carried out in order to survey the lower part of the bridge, since it was almost totally accessible. 400 terrestrial photos were acquired by the use of commercial (and cheaper) dSLR camera. The terrestrial images were carried out from multi point of views and according a convergent scheme. In this way, it was possible to observe the different parts that make up the bridge in every detail.

\subsection{Post-processing of the images: building of the 3D model using SFM/MVS approach}

The photogrammetric survey generated two image datasets of images, one produced by the aerial survey and the other by the terrestrial one. A total amount of 1371 images were produced (about of 5.5 GB).

The processing of terrestrial and aerial images was carried out using Agisoft Photoscan software, which allows you to create a 3D model using different simple processing steps. In particular, in the first phase, Agisoft PhotoScan detects the points in the source photos that are stable from the point of view and changes in lighting and generates a descriptor for each point based on its local neighbourhood. This approach is similar to the SIFT (ScaleInvariant Feature Transform) algorithm but uses different algorithms for a slightly higher alignment quality.

In order to increase the accuracy of the position and orientation of the cameras and select the actual object of the survey, special masks have been created by images not related to the area in question.

In self-calibration mode, all images (terrestrial and aerial) were aligned with high precision. Once the images are aligned, Agisoft PhotoScan has created a sparse point cloud (about 2 million points) that provides a three-dimensional approximation of the scene observed through the images. Subsequently, the software creates a dense point cloud offering different options to generate dense point clouds (Low, Medium, High and Very High). The choice of an option is linked to the morphological complexity of the object to be detected and to the type of PC used for data processing. In this case study, the "Medium" option was used and, 
at the end of the processing, about 53 million points were generated.

In order to effectively reduce the calculation times of the mesh construction, starting from the dense point clouds obtained in the project, the network processing available in Agisoft Photoscan was exploited.

In this case study, two separate chunks were built. In the Table 2 the number of the projections and the error of the single chunk are reported.

\begin{tabular}{|c|cc|cc|}
\hline Dataset & \multicolumn{2}{|c|}{ Projections } & \multicolumn{2}{c|}{$\begin{array}{c}\text { Error } \\
\text { (pixel) }\end{array}$} \\
& $\min$ & $\max$ & $\min$ & $\max$ \\
\hline Aerial & 1831 & 2426 & 0.524 & 0.8427 \\
Terrestrial & 4031 & 5114 & 0.622 & 0.247 \\
\hline
\end{tabular}

Table 2. Report on image matching for the two datasets

Therefore, in order to carry out the photogrammetric survey of this bridge, it was necessary to integrate the datasets of the photos obtained with the drone and those generated by the reflex camera. From an operational point of view, it means creating two point clouds in the project, one for the dataset produced by the drone, and the other for the reflex camera (survey performed with images acquired through a terrestrial survey).

Subsequently, through an algorithm "Iterative Closest Point" (ICP), i.e. an algorithm used to minimize the difference between two point clouds; the aerial and terrestrial point clouds were aligned in a single one able to represent the entire survey. In total, the final 3D model consists of approximately 1 million points.

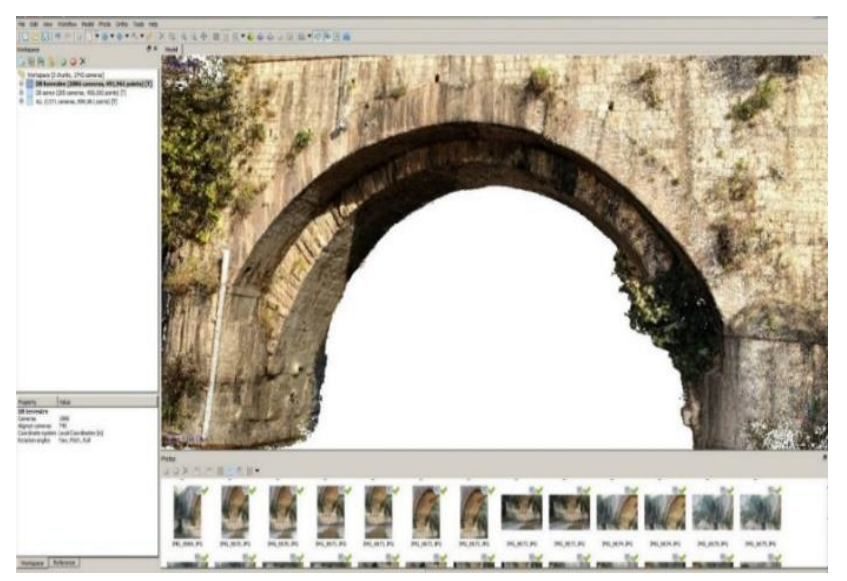

Figure 6. 3D dense point cloud representation in Photoscan environment

\subsection{Model scaling by topographic survey}

The model is scaled using Ground Control Points (GCPs). This GCPs may be determined by traditional topographic survey or GNSS (Global Navigation Satellite Systems) techniques (Lingua et al., 2017; Pepe, 2018b). In this case study, the scale model was obtained by recognizing on the images of 4 markers positioned on the superstructure of the bridge.

The coordinates of these markers were obtained by means of a special topographic survey performed with a total station.

The coordinates of each target were measured by the Pentax R$325(\mathrm{~N})$ total station equipped with a laser sensor for readings without prism whose characteristics are shown in the following Table 3.

\begin{tabular}{|c|c|c|c|}
\hline \multicolumn{2}{|c|}{ Features } & \multicolumn{2}{|c|}{ Parameters } \\
\hline \multirow{3}{*}{ Telescope } & Magnification & \multicolumn{2}{|c|}{$30 \mathrm{x}$} \\
\hline & $\begin{array}{l}\text { Optical } \\
\text { aperture }\end{array}$ & \multicolumn{2}{|c|}{ 45mm (EDM45mm) } \\
\hline & $\begin{array}{l}\text { Resolving } \\
\text { power }\end{array}$ & \multicolumn{2}{|c|}{$3 "$} \\
\hline \multirow{7}{*}{ EDM } & Laser class & \multicolumn{2}{|c|}{ Class 3R/ Class 2 (Switchable) } \\
\hline & \multirow{4}{*}{$\begin{array}{l}\text { Measurement } \\
\text { range }\end{array}$} & Reflectorless & $\begin{array}{l}1.5 \mathrm{~m} \sim 270 \mathrm{~m} \\
\text { (Long range } \\
\text { mode) }\end{array}$ \\
\hline & & Mini prism & $\begin{array}{l}1.5 \mathrm{M} \sim 1100 \mathrm{~m} \\
(1600 \mathrm{~m}) *(1)\end{array}$ \\
\hline & & $\begin{array}{l}\text { Single element } \\
\text { prism }\end{array}$ & $\begin{array}{l}1.5 \mathrm{~m} \sim 3000 \mathrm{~m} \\
(4000 \mathrm{~m}) *(2)\end{array}$ \\
\hline & & Reflector sheet & $\begin{array}{l}1.5 \mathrm{~m} \sim 600 \mathrm{~m} \\
(800 \mathrm{~m}) *(3)\end{array}$ \\
\hline & \multirow{2}{*}{ Accuracy } & $\begin{array}{l}\text { Prism, Reflector } \\
\text { sheet }\end{array}$ & $\begin{array}{l} \pm(2+2 \mathrm{ppm} \times \mathrm{D}) \\
\mathrm{mm}\end{array}$ \\
\hline & & Reflectorless & $\begin{array}{l} \pm(5+3 p p m \times D) \\
m m *\end{array}$ \\
\hline \multirow{2}{*}{$\begin{array}{c}\text { Angle } \\
\text { Measurement }\end{array}$} & $\begin{array}{l}\text { Accuracy (ISO } \\
17123-3 \text { ) }\end{array}$ & \multicolumn{2}{|c|}{$5 "$} \\
\hline & Compensator & \multicolumn{2}{|c|}{ Dual Axis } \\
\hline
\end{tabular}

Table 3. Technical and performance characteristics of the total station used for the survey

The report of the polar coordinates is shown in the following table 4 , where the reflector height was set to value 0 (the GCPs were determined without the use of prism).

\begin{tabular}{|c|c|c|c|c|}
\hline ID & $\begin{array}{c}\text { Horizontal } \\
\text { Angle } \\
\text { (gon) }\end{array}$ & $\begin{array}{c}\text { Zenith } \\
\text { angle } \\
\text { (gon) }\end{array}$ & $\begin{array}{c}\text { Real } \\
\text { distance } \\
(\mathrm{m})\end{array}$ & $\begin{array}{c}\text { Horizontal } \\
\text { distance } \\
(\mathrm{m})\end{array}$ \\
\hline 101 & 57.9508 & 106.0786 & 10.968 & 11.018 \\
102 & 91.7626 & 106.8010 & 9.808 & 9.864 \\
103 & 87.6390 & 101.1188 & 51.487 & 51.495 \\
104 & 80.9230 & 101.1814 & 51.596 & 51.605 \\
\hline
\end{tabular}

Table 4. Polar coordinates of the markers

Defining the average altitude zero on the station point named 100, it was possible to obtain the altimetry of the points. The processing was performed using a special tool developed in the Matlab environment. The coordinates of the GCPs, referred into a local reference system, are reported in the following table (Table 5)

\begin{tabular}{|c|c|c|c|}
\hline ID & $\begin{array}{c}\mathrm{X} \\
(\mathrm{m})\end{array}$ & $\begin{array}{c}\mathrm{Y} \\
(\mathrm{m})\end{array}$ & $\begin{array}{c}\mathrm{Z} \\
(\mathrm{m})\end{array}$ \\
\hline 101 & 6.729 & 8.661 & -1.050 \\
102 & 1.266 & 9.726 & -1.052 \\
103 & 9.934 & 50.519 & -0.905 \\
104 & 15.231 & 49.297 & -0.957 \\
\hline
\end{tabular}

Table 5. Target coordinates in a local reference system

Finally, by recognizing the points chosen as markers on the photos, Photoscan software performs a roto-translation scaling the $3 \mathrm{D}$ model. The root mean square value calculated on the model on GCPs was $0.011 \mathrm{~m}$.

\subsection{Qualitative and quantitative analysis of the masonry bridge}

Once realized the model, a qualitative and quantitative analysis is carried out. As regards the qualitative analysis, the visual inspection can be used in order to check the state of preservation of the upper part. Therefore, using the photogrammetric 
approach, it is possible to faithfully reconstruct the arches of the bridge according coloured mesh (Figure 7.a). In addition, reducing the number of mesh (decimated mesh), it was possible to emphasize the view of the several arches of the bridge, Indeed, according wireframe model, the arch of the I century A.D. was red-coloured while the external one built in the nineteenth century (Figure 7.b).

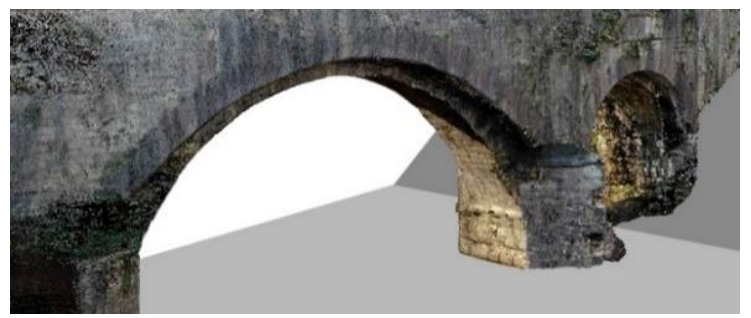

(a)

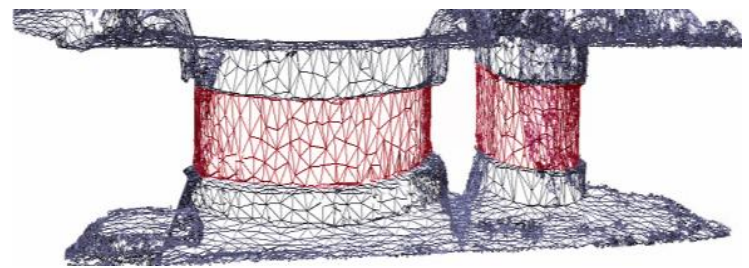

(b)

Figure 7. 3D representation of the arches of the bridge a) 3D of the San Cono's bridge arches; b) Plan view in wireframe mode of the (decimalized) mesh of the arches

A detail that characterizes the structure is, unfortunately, a rather abundant vegetation present in several parts of the structure. This vegetation, beyond to hide the beauty of the bridge, could also compromise the integrity of the structure.

The stacks located in the bed of a watercourse, generally arranged in the direction of the stream, have both appendages, upstream and downstream, called appendages with the function of gradually modifying the section of the riverbed, of diverting the material transported by the river and, of consequence, by reducing the turbulence of the current. In this way it is possible to reduce the risk of erosion of the bottom.

As regards the quantitative analysis, the creation of suitable surfaces for the structural modelling of the bridge, starting from a 3D model according to "dense point cloud", may take place along different ways.

In general, the first obstacle is represented by the presence of thick vegetation on the structure to be investigated. In fact, the elimination of vegetation has created holes within the structure. Therefore, the further difficulty in modelling was the reconstruction of the geometry of the bridge covered by vegetation.

Several pipelines have been examined. The most efficient of the several possible pipelines can thus be outlined:

\section{import of point cloud in Rhinoceros software;}

creation of objects in Rhino;

creation of structural objects in structural analysis software.

As indicated in the previous pipeline, the first step was to import the point cloud into the Rhinoceros software through the use of special plug-in called "Arena". This plug-in allowed an optimal management of the point cloud; indeed, it was possible to create detailed profiles in the specific sections (Figure 8).

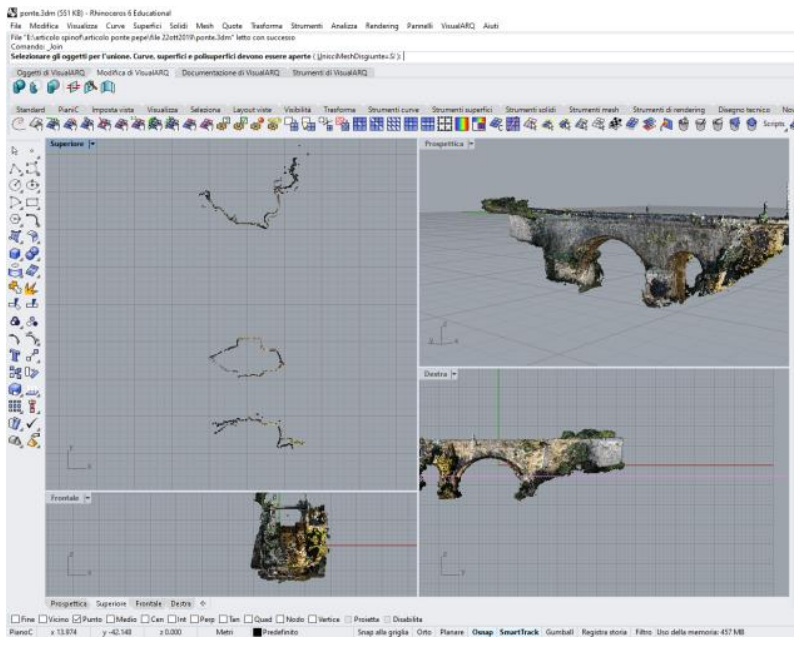

Figure 8. Extraction of sections from point cloud

In this (software) environment, the complex and irregular shapes of the bridge were created according to nurb geometries. In this way, it was also possible to differentiate the different elements of the bridge and define, at the same time, the different geometries of the pylons, double vaults and retaining walls. The characterization of each structural element allows each of them to be assigned a specific material. In order to dissect the vault, a geometric construction with projecting beams has been created which is able to define the precise spatial position of the sections. Once the sections were defined, nurbs connecting surfaces were built. Due to the irregular geometries, it was necessary to use an additional plug-in developed within Rhino, called "Evolut", which was able to generate highly complex and sophisticated nurbs surfaces. Therefore, using this method, the single and double vaulted bridge pylons, the retaining walls and the road were built through the sections and surfaces, as shown in the Figure 9.

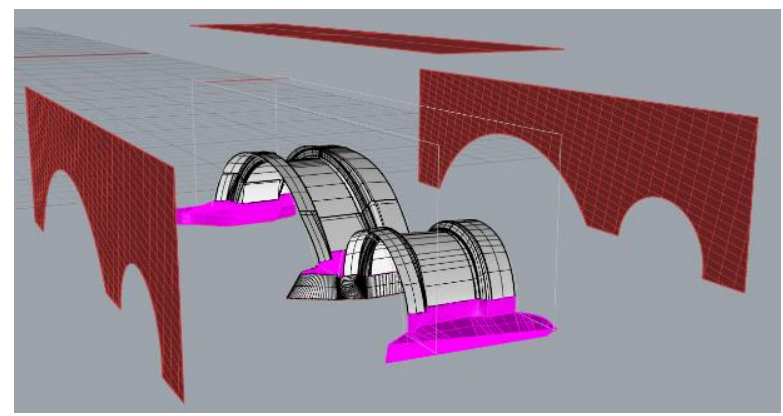

Figure 9. Construction of the structural parts of the bridge: containment walls, vaults and pillars.

Subsequently, the surfaces were imported into the GTS NX structural software. GTS NX is a comprehensive finite element analysis software package that is equipped to handle the entire range of structural design applications. In this type of software, nurbs surfaces cannot be imported but solids must be built (through the aforementioned surfaces). As a result, each nurbs surface was transformed into a solid through modelling in Rhino. Once the solid geometric objects were exported in GTS-NX software, it was possible to create structural meshes. For example, is shown in the Figure 10, a view of the vault of the bridge in GTS NX software (import from Rhino as a solid in parasolid format). 


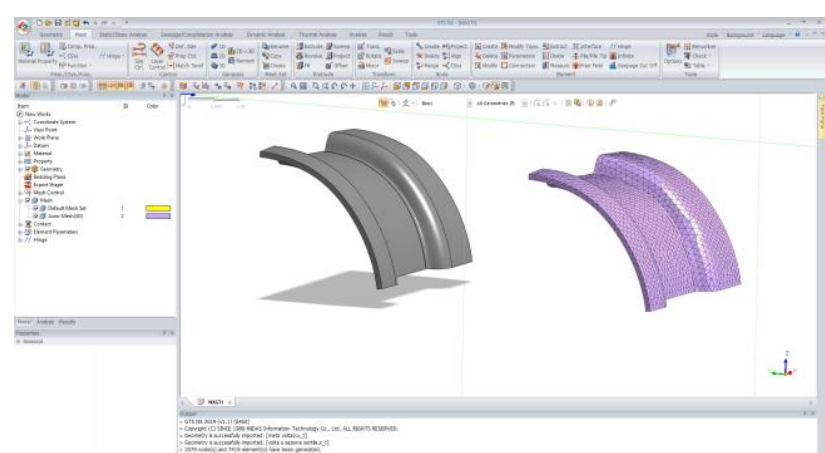

Figure 10. View of the vault of the bridge in GTS NX software

In order to perform the structural calculation, these objects were constrained and subjected to loads. Since that the several objects already distinct from one another during the mesh creation operation, it was possible to assign them specific materials. In this way, the single geometric object was parameterized, and consequently, each of them had appropriate values of the elastic modulus. Since the geometric objects are made of masonry, the structural analysis was performed using the constitutive model of Mohr Coulomb.

\section{CONCLUSIONS}

The integration of terrestrial and aerial photogrammetric techniques allowed to obtain an accurate 3D model of masonry bridge. In the data acquisition step, the use of UAV aerial platform was applied with success to survey a lot of detail of the superstructure of the bridge which could not be obtained by terrestrial survey. As regards the post-processing of the image, the elevated automation and high accuracy achievable by commercial software based on SfM-MVS approach allowed to build a 3D point cloud and 3D mesh with texture. So, starting from a geomatics surveys, it was identified and applied a novel and efficient procedure able to obtain a 3D model suitable for structural analysis. Indeed, despite the 3D model of masonry bridge showed the presence of dense vegetation in some parts of the structure, this criticality was overcome reconstructing the geometry in Rhino environment which specializes in 3D surface management and modelling.

\section{REFERENCES}

Altuntas, C., Pehlivanl,, M. E., Kurban, S., 2017. Low-Cost 3D Imaging and Measurement Techniques for Documentation of Meram Masonry Arch Bridge in Turkey. International Journal of Sensors and Sensor Networks, 5(5), p.63.

Angelini, M. G., Baiocchi, V., Costantino, D., Garzia, F. 2017. Scan to BIM for 3D reconstruction of the papal basilica of Saint Francis in Assisi in Italy. International Archives of the Photogrammetry, Remote Sensing \& Spatial Information Sciences, 42.

Calì, M., Ambu, R., 2018. Advanced 3D Photogrammetric Surface Reconstruction of Extensive Objects by UAV Camera Image Acquisition. Sensors, 18(9), p. 2815.

Cucchiaro, S., Maset, E., Fusiello, A., Cazorzi, F., 2018. 4d-sfm photogrammetry for monitoring sediment dynamics in a debrisflow catchment: software testing and results comparison. International Archives of the Photogrammetry, Remote Sensing \& Spatial Information Sciences, 42(2).
Enac, 2018. Regulation RPAS_Issue_2_Rev_4 (https://www.enac.gov.it/sites/default/files/allegati/2018Lug/Regulation_RPAS_Issue_2_Rev_4_eng.pdf)

Jiang, R., Jáuregui, D. V., White, K. R., 2008. Close-range photogrammetry applications in bridge measurement: Literature review. Measurement, 41(8), 823-834.

Jáuregui, D., Tian, Y., Jiang, R., 2006. Photogrammetry applications in routine bridge inspection and historic bridge documentation. Transportation Research Record: Journal of the Transportation Research Board, (1958), 24-32.

Kouimtzoglou, T., Stathopoulou, E. K., Georgopoulos, A., 2017. Image-Based 3D Reconstruction Data as AN Analysis and Documentation Tool for Architects: the case of Plaka Bridge in Greece, The International Archives of the Photogrammetry, Remote Sensing and Spatial Information Sciences.

Lingua, A., Noardo, F., Spanò, A., Sanna, S., \& Matrone, F. 2017. 3D model generation using oblique images acquired by UAV International Archives of the Photogrammetry, Remote Sensing \& Spatial Information Sciences, 42.

Lorenzo, H., Arias, P., Armesto, J., Rial, F. I., Pereira, M., Novo, A., Solla, M., 2007. Documentation and evaluation of historic masonry arch bridges by means of geomatic techniques. In Proceedings of 5th International Conference on Arch Bridges (ARCH'07), 373-380.

Luhmann, T., Robson, S., Kyle, S., Harley, I., 2007. Close range photogrammetry, Wiley.

Murtiyoso, A., Grussenmeyer, P., Börlin, N., Vandermeerschen, J., Freville, T. 2018. Open source and independent methods for bundle adjustment assessment in close-range UAV photogrammetry. Drones, 2(1), 3.

Pepe, M., Fregonese, L., Scaioni, M., 2018. Planning airborne photogrammetry and remote-sensing missions with modern platforms and sensors. European Journal of Remote Sensing, 51(1), 412-436.

Pepe, M., 2018a. Image-based methods for metric surveys of buildings using modern optical sensors and tools: from 2D approach to 3D and vice versa, International Journal of Civil Engineering and Technology.

Pepe, M. 2018b. CORS architecture and evaluation of positioning by low-cost GNSS receiver. Geodesy and Cartography, 44(2), 36-44.

Rahaman, H., Champion, E., 2019. To 3D or Not 3D: Choosing a Photogrammetry Workflow for Cultural Heritage Groups. Heritage, 2(3), 1835-1851.

Remondino, F., Worth a thousand words - photogrammetry for archaeological 3D surveying, in: Opitz, R.S., Cowley, D.C. (Eds.), Interpreting archaeological topography: airborne laser scanning, 3D data, and ground observation, occasional publication of the aerial archaeology research group no. 5, Oxbow Books, Oakville, CT, 2013, 115-122.

Şeker, D. Z., Avşar, E. Ö., Aydar, U., 2006. Modeling of Historical Bridges Using Photogrammetry and Virtual Realty. In: XXIII FIG Congress and XXIX General Assembly - Shaping the Change, Munich, Germany, p.12. 